\title{
Validation of a Thermal Conductivity \\ Measurement System for Fuel Compacts
}

\author{
ASME/JSME $20118^{\text {th }}$ Thermal \\ Engineering Joint Conference
}

The INL is a

U.S. Department of Energy

National Laboratory

operated by

Battelle Energy Alliance

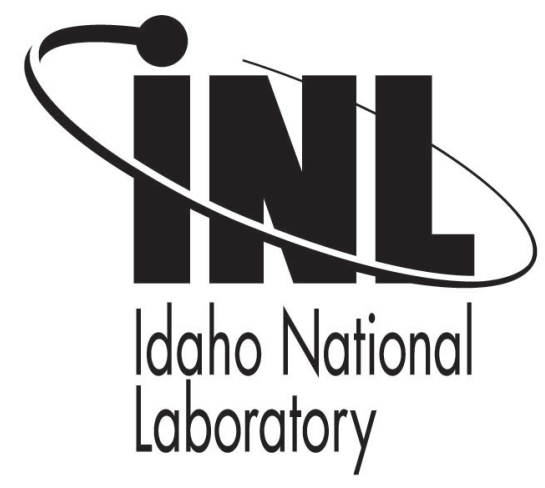

\section{Colby Jensen \\ Changhu Xing \\ Heng Ban \\ Jeffrey Phillips}

\section{March 2011}

This is a preprint of a paper intended for publication in a journal or proceedings. Since changes may be made before publication, this preprint should not be cited or reproduced without permission of the author. This document was prepared as an account of work sponsored by an agency of the United States Government. Neither the United States Government nor any agency thereof, or any of their employees, makes any warranty, expressed or implied, or assumes any legal liability or responsibility for any third party's use, or the results of such use, of any information, apparatus, product or process disclosed in this report, or represents that its use by such third party would not infringe privately owned rights. The views expressed in this paper are not necessarily those of the United States Government or the sponsoring agency. 


\section{AJTEC2011-44557}

\section{VALIDATION OF A THERMAL CONDUCTIVITY MEASUREMENT SYSTEM FOR FUEL COMPACTS}

\author{
Colby Jensen, Changhu Xing, and Heng Ban \\ Department of Mechanical and Aerospace Engineering \\ Utah State University \\ 4130 Old Main Hill \\ Logan, UT 84341-4130 \\ colby.jensen@aggiemail.usu.edu
}

\author{
Jeffrey Phillips \\ Idaho National Laboratory \\ 2525 Fremont Avenue \\ Idaho Falls, ID 83415
}

\section{ABSTRACT}

A high temperature guarded-comparative-longitudinal heat flow measurement system has been built to measure the thermal conductivity of a composite nuclear fuel compact. It is a steady-state measurement device designed to operate over a temperature range of $300 \mathrm{~K}$ to $1200 \mathrm{~K}$. No existing apparatus is currently available for obtaining the thermal conductivity of the composite fuel in a non-destructive manner due to the compact's unique geometry and composite nature. The current system design has been adapted from ASTM E 1225. As a way to simplify the design and operation of the system, it uses a unique radiative heat sink to conduct heat away from the sample column. A finite element analysis was performed on the measurement system to analyze the associated error for various operating conditions. Optimal operational conditions have been discovered through this analysis and results are presented. Several materials have been measured by the system and results are presented for stainless steel 304, inconel 625 , and $99.95 \%$ pure iron covering a range of thermal conductivities of $10 \mathrm{~W} / \mathrm{m} * \mathrm{~K}$ to $70 \mathrm{~W} / \mathrm{m} * \mathrm{~K}$. A comparison of the results has been made to data from existing literature.

\section{NOMENCLATURE}

$A_{m} \quad$ Cross-sectional area of meter bars, $\mathrm{A}_{\mathrm{m}}=\pi \mathrm{r}_{\mathrm{b}}^{2}$, $\left[\mathrm{m}^{2}\right]$

$A_{S} \quad$ Cross section area of test specimen, $\mathrm{A}_{\mathrm{S}}=\pi \mathrm{r}_{\mathrm{s}}^{2}$, $\left[\mathrm{m}^{2}\right]$

$h_{b} \quad$ Height of meter bars, [m]

$h_{s} \quad$ Height of test specimen, [m]

$k_{g} \quad$ Thermal conductivity of nickel guard as a function of temperature, $[\mathrm{W} / \mathrm{m} / \mathrm{K}]$ $k_{i} \quad$ Thermal conductivity of insulation as a function of temperature, $[\mathrm{W} / \mathrm{m} / \mathrm{K}]$

$k_{m} \quad$ Thermal conductivity of meter bar as a function of temperature, $[\mathrm{W} / \mathrm{m} / \mathrm{K}]$

$k_{s} \quad$ Inputted thermal conductivity of test specimen, $[\mathrm{W} / \mathrm{m} / \mathrm{K}]$

$k_{s c} \quad$ Calculated thermal conductivity of test specimen, $[\mathrm{W} / \mathrm{m} / \mathrm{K}]$

$q_{1} \quad$ Heat flow in first meter bar, [W]

$q_{2} \quad$ Heat flow in second meter bar, [W]

$r \quad$ Unit vector in radial direction, [m]

$r_{b} \quad$ Radius of guard, [m]

$r_{g} \quad$ Radius of guard, [m]

$r_{i} \quad$ Outside radius of insulation, [m]

$r_{s} \quad$ Radius of test specimen, [m]

$T_{1-6} \quad$ Temperature monitors at positions $\mathrm{z}_{1}$ through $\mathrm{z}_{6},[\mathrm{~K}]$

$Z_{1-6}$ Positions from the bottom, [m]

$T_{c b} \quad$ Meter bar temperature at the cold end, $[\mathrm{K}]$

$T_{c g} \quad$ Guard temperature at the cold end, $\mathrm{T}_{\mathrm{cg}}=\mathrm{T}_{\mathrm{cb}}+\Delta \mathrm{T}_{\mathrm{cg}},[\mathrm{K}]$

$T_{h b} \quad$ Meter bar temperature at the hot end, [K]

$T_{h g} \quad$ Guard temperature at the hot end, $\mathrm{T}_{\mathrm{hg}}=\mathrm{T}_{\mathrm{hb}^{-}}$ $\Delta \mathrm{T}_{\mathrm{bg}},[\mathrm{K}]$

$\overline{T_{S}} \quad$ Average temperature of test sample, $[\mathrm{K}]$

$\bar{T}_{1} \quad$ Average temperature of first meter bar, $[\mathrm{K}]$

$\overline{T_{2}} \quad$ Average temperature of second meter bar, $[\mathrm{K}]$

$z \quad$ Unit vector in axial direction, [m]

$\Delta T_{b g} \quad$ Temperature difference between meter bar and guard, [K]

$\Delta T_{h c} \quad$ Temperature difference for meter bar at hot and cold ends, [K]

$\Delta T_{a} \quad$ Temperature deviation of guard averaged 
temperature from specimen mean temperature, [K]

$\Delta T_{s} \quad$ Measured temperature difference across sample, [K]

$\Delta T_{1} \quad$ Measured temperature difference across first meter bar, [K]

$\Delta T_{2} \quad$ Measured temperature difference across second meter bar, $[\mathrm{K}]$

$\Delta Z_{s} \quad$ Distance between temperature measurement points in test sample, [m]

$\Delta Z_{1} \quad$ Distance between temperature measurement points in first meter bar, [m]

$\Delta Z_{2} \quad$ Distance between temperature measurement points in second meter bar, [m]

$\sigma_{A_{m}} \quad$ Uncertainty in meter bar area

$\sigma_{A_{S}} \quad$ Uncertainty in test sample area

$\sigma_{k_{m}} \quad$ Uncertainty in meter bar thermal conductivity

$\sigma_{k_{s}} \quad$ Uncertainty in test sample thermal conductivity

$\sigma_{\Delta T_{m}} \quad$ Uncertainty in temperature difference in the meter bars

$\sigma_{\Delta T_{S}} \quad$ Uncertainty in temperature difference in the test sample

$\sigma_{\Delta Z_{m}} \quad$ Uncertainty in the distance between thermocouples in the meter bars

$\sigma_{\Delta Z_{S}} \quad$ Uncertainty in the distance between thermocouples in the test sample

\section{INTRODUCTION}

With the development of new materials and technologies in the effort to bring about the nuclear renaissance, the capability to characterize the thermomechanical and thermophysical properties of new materials including fuels is a vital piece of this development process. In many cases the inherent composition and geometry in which these materials are used, as well as the environments in which they are required to perform requires specialized measurement tools. The development of new, specialized measurement tools requires careful testing to validate the system performance. The purpose of this paper is to demonstrate the validation process for one such specialized system.

Thermal conductivity is an important thermophysical property needed for effectively predicting fuel performance. As part of the Next Generation Nuclear Plant (NGNP) program, the thermal conductivity of a composite fuel needs to be measured over a temperature range characteristic of its usage $(400 \mathrm{~K}$ to $1100 \mathrm{~K})$. The fuel is comprised of layered particles $1 \mathrm{~mm}$ in diameter sintered together in a graphite matrix in the form of a cylindrical compact. The compact has a nominal length of $25 \mathrm{~mm}(\sim 1$ ") and nominal diameter of $12.3 \mathrm{~mm}(\sim 0.5$ ") which cannot be altered for measurement.

\section{Thermal Conductivity Measurement}

Because the selection of measurement method was an important part of the work in this project, a brief review of thermal conductivity measurement methods is warranted to be included in this work. Two general classifications of thermal conductivity measurement methods are: (1) steady-state and (2) transient. In either case the measurement may be absolute or comparative, the difference being that comparative methods require the property of another material in the calculation of a test sample thermal conductivity, typically a distinct disadvantage. A previous paper includes a more complete overview of common methods [1].

\section{Comparative-Guarded-Axial Heat Flow Method}

Because of the cylindrical shape and medium to high thermal conductivity $(10-60 \mathrm{~W} / \mathrm{m} / \mathrm{K})$ expected of the nuclear fuel to be measured, an axial heat flow method was selected to be used. Further, due to the small size of the sample and the desired temperature range for measurement, the comparative axial heat flow technique was selected. The comparative axial heat flow method or for the case of cylindrical samples and meter bars, the cut-bar technique, has been used since the 1930's [2] and was more completely studied and developed in the 1950's and 1960's by Ballard et al. [3], Morris and Hust [4], Francl and Kingery [5], and Mirkovich [6] among others. Laubitz [7] questioned the claimed accuracy of such measurements, but later studies performed by Sweet et al [8] and Pillai and George [9] reported accuracies independent of the uncertainty of the reference sample, to be better than $\pm 5 \%$. In 1987 the American Society of Testing and Materials (ASTM) produced a standard for this method, ASTM E 1225 [10] which was revised in 2004. Also noteworthy for the purposes of this project, Babelot et al. performed tests on a modified commercial comparative thermal conductivity apparatus that was to be used in a glove box [11].

In literature, the use of steady state methods for measuring thermal conductivity has become progressively scarcer over the last 40 years. Few detailed analysis of such systems have been reported. Didion performed a mathematical analysis of a comparative-guarded-axial heat flow system in which the guard temperature distribution was matched at the hot and cold ends [12]. Using these conditions, a compilation of design charts were created. These charts were used in the design of the current system.

In this technique, a test sample of unknown thermal conductivity is sandwiched between two reference samples of known thermal conductivity forming what will be referred to as a sample column. A temperature gradient is set up and measured through the samples using a heater on one end of the sample column and a cold sink on the other end. A guarding system is employed to prevent/reduce radial heat losses from the sample column. Figure 1 shows a simple schematic of the technique. From the measured gradients in the reference 


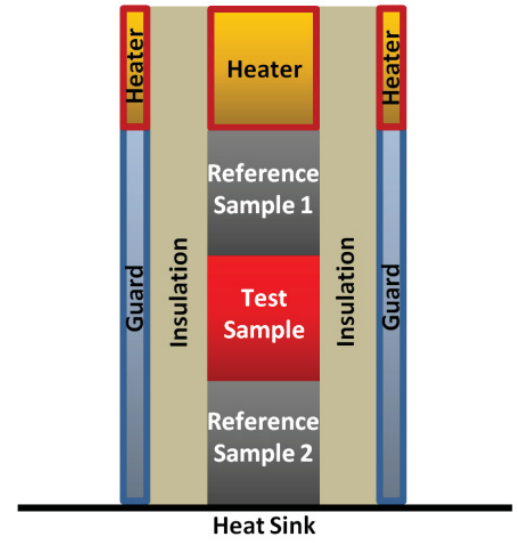

FIGURE 1. SIMPLE SCHEMATIC OF COMPARATIVEGUARDED-AXIAL HEAT FLOW TECHNIQUE SETUP

samples, using the cross-sectional area of the samples, the heat flowing through the samples may be calculated.

$$
q_{1,2}=k_{m}\left(\overline{T_{1,2}}\right) A_{m} \frac{\Delta T_{1,2}}{\Delta Z_{1,2}}
$$

Thus the reference samples act much like heat flow meters and are often referred to as meter bars. Using the measured flux in the meter bars and the measured temperature gradient in the test sample, the thermal conductivity of the test sample at its average temperature may be calculated.

$$
k_{S}\left(\bar{T}_{S}\right)=\frac{q_{1}+q_{2}}{2} \frac{\Delta Z_{S}}{A_{S} \Delta T_{S}}
$$

\section{PHYSICAL DESIGN AND CONSTRUCTION}

A detailed description of the design and operation of the description of the design and operation of the TRISO fuel thermal conductivity measurement system (TFTCMS) can be found in a previous paper [1]. The TFTCMS has been designed to accommodate the TRISO fuel geometry and expected thermal conductivity value. Much of the selection of geometry, sizing of components, and materials is based on the recommendations of from an analysis performed by Didion [12] and the guidelines given by ASTM E 1225-04 [10].

Although the thermal conductivity of TRISO fuel is unknown, the TFTCMS is designed to measure has an expected range of thermal conductivity of $\sim 10 \mathrm{~W} / \mathrm{m}^{*} \mathrm{~K}$ up to $\sim 70 \mathrm{~W} / \mathrm{m}^{*} \mathrm{~K}$. The components of the system were selected for use with a sample with this expected thermal conductivity range as well as being capable of withstanding a $900^{\circ} \mathrm{C}$ environment. Figure 2 shows a schematic of the major components of the measurement section of the system.

The three primary purposes of this design are:

1. Create a controlled, one dimensional, steady-state temperature gradient through the sample column (test sample and adjacent reference samples). This is accomplished through the use of a surrounding layer of insulation as well as

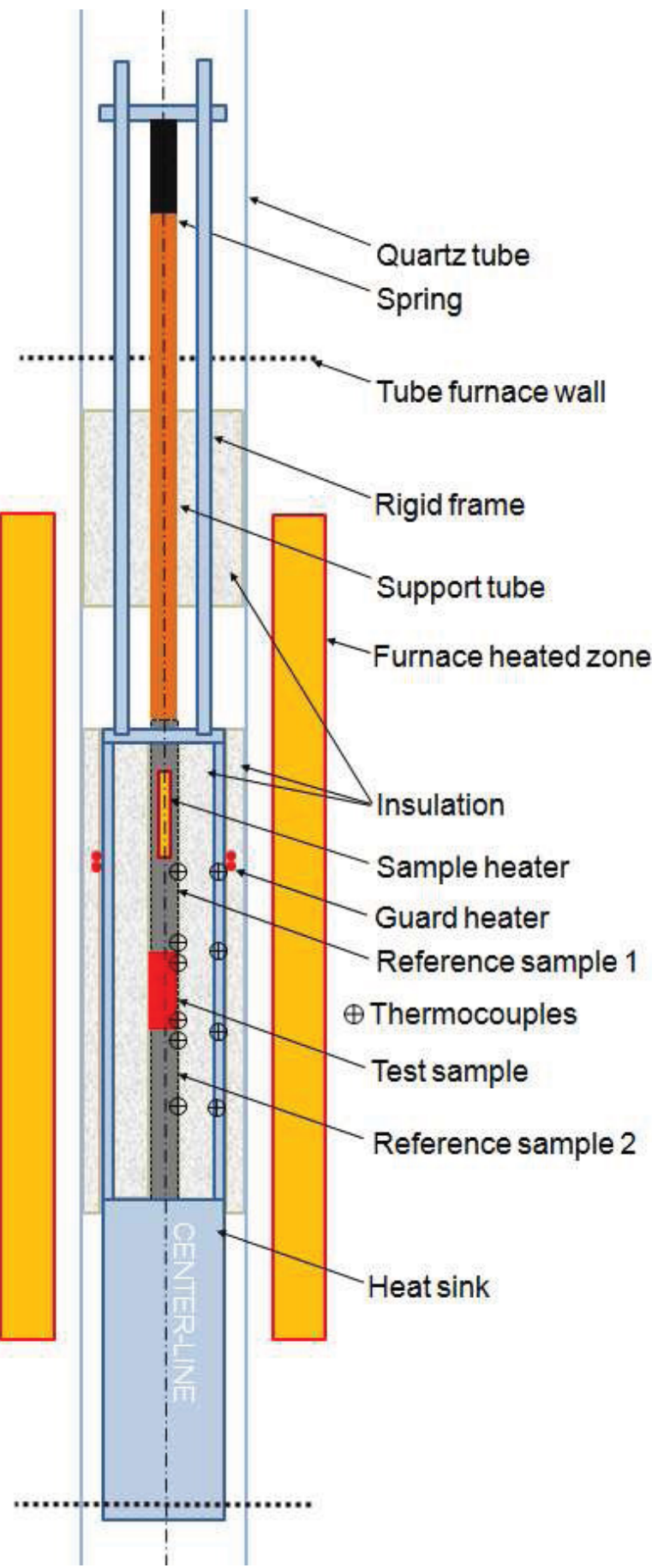

FIGURE 2. SCHEMATIC OF MEASUREMENT SECTION OF THE TRISO FUEL THERMAL CONDUCTIVITY MEASUREMENT SYSTEM (TFTCMS).

a guard tube that will be matched closely to the temperature gradient in the central sample column.

2. Create reproducible conditions in the measurement region by use of a spring system to apply a constant pressure 
through the central column. The contact resistances at the interfaces of the experimental sample and reference samples will thus be better reproducible.

3. Measure steady-state temperature gradients in the experimental sample and reference samples from which thermal conductivity may be calculated. Figure 2 shows the approximate thermocouple locations used in these measurements. Also additional temperature measurements along the experimental region may be used to be able to estimate radial heat losses/gains from the sample column.

For measurements along the sample column $0.127 \mathrm{~mm}$ $(0.005$ ") Type $\mathrm{N}$ thermocouples are used. For measurements along the guard, $0.254 \mathrm{~mm}(0.01$ ") Type $\mathrm{N}$ thermocouples are used.

An important aspect of the design of the TFTCMS is the use of a radiative heat sink which helps to establish a temperature gradient through the guard and sample column. The use of radiative heat sink has both advantages and disadvantages. The main disadvantage is that less control is provided for the temperature gradients in the guard and sample column. This disadvantage is also an advantage because its selection greatly simplifies the design and operation of the system. A closed-loop temperature controlled heat sink is not required as is typical for similar systems. Thus the temperature difference between the sample column and the guard near the heat sink is somewhat free to float.

Due to the unique heat sink design and consequential operational conditions, finite element studies of the sample column and guard under various operational conditions have been performed in order that the disadvantage of less control over the system temperature profiles may be overcome.

\section{System Validation}

The validation of the newly designed system is an important step in its development and is recommended by ASTM E 1225 [10]. As part of this process, a finite element study was performed on the measurement section of the apparatus as well as the measurement of several test samples of known thermal conductivities which are called reference samples in this work (although they are not certified reference samples). The finite element analysis (FEA) was performed after the initial testing was done

\section{FINITE ELEMENT MODELING}

\section{Computational Setup}

Figure 3 presents a schematic illustration of the cut-bar technique used in this analysis. Due to its axisymmetric geometry, the problem can be solved in a 2-D cylindrical coordinate system. A specimen with unknown thermal conductivity is sandwiched between a pair of meter bars. A temperature gradient along the sample column is created by keeping the hot end at $\mathrm{T}_{\mathrm{hb}}$ and cold end at $\mathrm{T}_{\mathrm{cb}}$. The temperature difference $\Delta \mathrm{T}_{\mathrm{hc}}$ between the two ends is set to be a constant value. The composite column structure is surrounded by the insulation material. In this setup, diatomaceous earth powder is used due to its low thermal conductivity [10]. This powder layer is encased by a guard as a rigid support which has a linear temperature distribution from the hot-side temperature, $\mathrm{T}_{\mathrm{gh}}$ to cold-side temperature, $\mathrm{T}_{\mathrm{gc}}$.

In ASTM E 1225, two guard temperature schemes are recommended [10]: (1) guard temperature gradient matched to the test stack and (2) isothermal guard with a temperature equal to the average temperature of the specimen. However, in this analysis, a parametric variation of the temperature difference between the guard and meter bars is done while keeping the average temperatures of both the guard and the sample column the same. Thus if the guard hot end is $\Delta \mathrm{T}_{\mathrm{bg}}$ degrees cooler than the hot end of the meter bar; the guard cold end is $\Delta \mathrm{T}_{\mathrm{bg}}$ degrees hotter than the cold end of meter bar. When $\Delta \mathrm{T}_{\mathrm{bg}}$ changes from zero to half of the temperature difference, $\Delta \mathrm{T}_{\mathrm{hc}}$ of the whole setup, the guard temperate distribution varies from scheme (1) to (2) gradually. If certain deviation exists between the guard and specimen averaged temperatures, an additional $\Delta \mathrm{T}_{\mathrm{a}}$ is applied on the guard in addition to the guard temperature distribution.



FIGURE 3. SCHEMATIC ILLUSTRATION OF THE COMPARATIVE-GUARDED-LONGITUDINAL HEAT FLOW SYSTEM WITH APPLIED BOUNDARY CONDITIONS. 
The boundary condition for the insulation $\left(r_{b}<r<r_{i}\right)$ was set according to the solution for steady state 1-D heat flow between two constant temperature surfaces in the radial direction.

$$
T_{i}(r)=T_{h g, c g}+\Delta T_{b g} \frac{\ln \left(r / r_{i}\right)}{\ln \left(r_{b} / r_{i}\right)}
$$

Inside the domain, the temperature is calculated by the heat conduction equation.

$$
\frac{1}{r} \frac{\partial}{\partial r}\left(k \frac{\partial T}{\partial r}\right)+\frac{\partial}{\partial z}\left(k \frac{\partial T}{\partial z}\right)=0
$$

With an input of the thermal conductivity of specimen, the temperatures $T_{1}$ thru $T_{6}$ at positions $z_{1}$ thru $z_{6}$ respectively can be monitored after reaching steady state, thus mimicking the method and locations of measurement used in the real apparatus. The calculated thermal conductivity of specimen may be performed based on the previously described equations (1) and (2).

$$
\begin{aligned}
& q_{1}=k_{m}\left[\left(T_{1}+T_{2}\right) / 2\right] \frac{T_{2}-T_{1}}{z_{2}-z_{1}} A_{m} \\
& q_{2}=k_{m}\left[\left(T_{5}+T_{6}\right) / 2\right] \frac{T_{6}-T_{5}}{z_{6}-z_{5}} A_{m} \\
& k_{s c}=\frac{1}{2} \frac{q_{1}+q_{2}}{A_{s}} \frac{z_{4}-z_{3}}{T_{4}-T_{3}}
\end{aligned}
$$

Based on the specimen thermal conductivity range, as well as the guideline from ASTM standard [10] and work from Didion [12], the material of the meter bars was chosen as stainless steel 304 and the guard as nickel. The thermal conductivity of stainless steel, which increases nearly linearly with temperature over the temperature range of interest, can be found in [10] (recommended by [8]) and the thermal conductivity of nickel can be found in [13]. The temperature dependent data for both were input into the commercial software, COMSOL and interpolated with temperature.

The geometry of the test system was designed according to the guideline mentioned above and presented in Table 1. To test the appropriate working range and minimize the systematic error, parametric studies were performed on several parameters.

Two-dimensional structured grids were used in the simulations. To get reliable results, grid independence was tested for four mesh systems. The first case used 30 divisions

TABLE 1. GEOMETRY AND THERMOPHYSICAL PROPERTIES OF THE SYSTEM (UNITS ARE SHOWN IN NOMENCLATURE)

\begin{tabular}{|l|l|l|l|}
\hline $\mathrm{r}_{\mathrm{b}}$ & $\mathrm{r}_{\mathrm{s}}$ & $\mathrm{r}_{\mathrm{i}}$ & $\mathrm{r}_{\mathrm{g}}$ \\
\hline 0.00615 & 0.00615 & 0.022225 & 0.028575 \\
\hline $\mathrm{h}_{\mathrm{b}}$ & $\mathrm{h}_{\mathrm{s}}$ & $\mathrm{T}_{\mathrm{cb}}$ & $\mathrm{T}_{\mathrm{hb}}$ \\
\hline 0.0254 & 0.0254 & 848.15 & 898.15 \\
\hline
\end{tabular}

in the axial ( $\mathrm{z}$ ) direction and 25 divisions in the radial (r) direction. The mesh size of three consecutive cases was increased by a multiple of 2 in each direction in terms of the previous one. When using the densest case as the reference, the maximum error yielded from the coarsest case is only $0.06 \%$ with a test specimen thermal conductivity range of 5$100 \mathrm{~W} / \mathrm{m} / \mathrm{K}$. Thus the error induced by different mesh system is negligible.

\section{Numerical Results}

Figure 4 presents the percentage error generated by a comparison of computed thermal conductivity $\left(\mathrm{k}_{\mathrm{sc}}\right)$ to the inputted true value $\left(\mathrm{k}_{\mathrm{s}}\right)$ when $\Delta \mathrm{T}_{\mathrm{bg}}$ varying parametrically. The computation in Eq. (5) relies on an assumption that equal heat flow occurs on the cross section of both meter bars and specimen when a perfect match of temperature $\left(\mathrm{T}_{\mathrm{cb}}=\mathrm{T}_{\mathrm{cg}}\right.$ and $\mathrm{T}_{\mathrm{hb}}=\mathrm{T}_{\mathrm{hg}}$ ) is imposed on the guard. If it is true, computation of specimen thermal conductivity by Eq. (7) should not incur too much systematic error. In reality, however, the constant, 1-D heat flow assumption is rather weak due to the radial heat exchange with guard and axial heat shunting on the specimen and meter bar interface due to their different thermal conductivities. The proof of this may be seen from the percentage error when different thermal conductivities of the test specimen are considered.

At the working temperature range, shown in Table 1, the thermal conductivity of stainless steel 304 is approximately 24 $\mathrm{W} / \mathrm{m} / \mathrm{K}$, the insulation material is approximately $0.11 \mathrm{~W} / \mathrm{m} / \mathrm{K}$, and the guard is $69 \mathrm{~W} / \mathrm{m} / \mathrm{K}$. When $\Delta \mathrm{T}_{\mathrm{bg}}=0$, the error is negligible for a specimen with $\mathrm{k}_{\mathrm{s}}=25 \mathrm{~W} / \mathrm{m} / \mathrm{K}$ because the temperature gradient difference between meter bar and specimen is not significant. When $\mathrm{k}_{\mathrm{s}}$ increasingly deviates



FIGURE 4. PERCENTAGE ERROR YIELD BY CALCULATED AND INPUT SPECIMEN THERMAL CONDUCTIVITY WITH RESPECT TO THE VARIATION OF $\Delta T_{B G \text {. }}$ 
from $\mathrm{k}_{\mathrm{m}}$, the induced error becomes increasingly larger. Meanwhile, the low $\mathrm{k}_{\mathrm{s}}$ case has larger error compared with the high $\mathrm{k}_{\mathrm{s}}$ one because axial heat shunting and radial heat exchange is more significant for the low $\mathrm{k}_{\mathrm{s}}$ situation. When $\mathrm{k}_{\mathrm{s}}=5 \mathrm{~W} / \mathrm{m} / \mathrm{K}$, the ratio of $\mathrm{k}_{\mathrm{s}} / \mathrm{k}_{\mathrm{i}}$ is roughly 50 . For these conditions, the error is still around $11 \%$. If this ratio increases such that the radial heat flow is obstructed, the calculated error becomes smaller. Another important phenomenon is that the error resulting from low $\mathrm{k}_{\mathrm{s}}$ is positive (calculated value is larger than inputted one) whereas the error brought about by high $\mathrm{k}_{\mathrm{s}}$ is negative.

When $\Delta \mathrm{T}_{\mathrm{bg}}$ increases from zero to half of $\Delta \mathrm{T}_{\mathrm{hc}}$, the corresponding errors from all of the $\mathrm{k}_{\mathrm{s}}$ cases change linearly with a positive slope. For the cases when $\mathrm{k}_{\mathrm{s}}<\mathrm{k}_{\mathrm{m}}$, the errors increase in magnitude continuously. For $\mathrm{k}_{\mathrm{s}} \approx \mathrm{k}_{\mathrm{m}}$, the error increases from roughly zero at the "matching" condition to around $6 \%$ at the "isothermal" condition. However, for the cases when $\mathrm{k}_{\mathrm{s}}>\mathrm{k}_{\mathrm{m}}$, the negative errors approach zero (critical value of $\Delta \mathrm{T}_{\mathrm{bg}}$ ) with an increase of $\Delta \mathrm{T}_{\mathrm{bg}}$ and continue to increase after passing a critical value. Based on this analysis, it seems that the two recommended guard working conditions are not optimized and more attention should be paid to the selection of guarding conditions. If $\mathrm{k}_{\mathrm{s}}>\mathrm{k}_{\mathrm{m}}$, a lower temperature gradient on the guard compared to the sample column is helpful for eliminating systematic error. Thus, the optimum $\Delta \mathrm{T}_{\mathrm{bg}}$ is around $8{ }^{\circ} \mathrm{C}$ for $\mathrm{k}_{\mathrm{s}}=50 \mathrm{~W} / \mathrm{m} / \mathrm{K}$ and $13{ }^{\circ} \mathrm{C}$ for $\mathrm{k}_{\mathrm{s}}=100$ $\mathrm{W} / \mathrm{m} / \mathrm{K}$.

Since a lower temperature gradient on the guard is better for the large $\mathrm{k}_{\mathrm{s}}$ case, it is reasonable to assume that a higher temperature gradient on the guard is needed for small $\mathrm{k}_{\mathrm{s}}$ situations in order to reduce error. For $\mathrm{k}_{\mathrm{s}}=15$ or $5 \mathrm{~W} / \mathrm{m} * \mathrm{~K}$ cases, one can observe that the errors approach zero with a negative increase of $\Delta \mathrm{T}_{\mathrm{bg}}$, viz. an increase of temperature gradient of the guard. Beyond a critical $\Delta \mathrm{T}_{\mathrm{bg}}$, the error becomes negative and increases in magnitude with a further increase of negative $\Delta \mathrm{T}_{\mathrm{bg}}$. Thus for $\mathrm{k}_{\mathrm{s}}=15$ and $5 \mathrm{~W} / \mathrm{m}^{*} \mathrm{~K}$, the critical $\Delta \mathrm{T}_{\mathrm{bg}}$ is around $-6^{\circ} \mathrm{C}$ and $-21{ }^{\circ} \mathrm{C}$ respectively.

Figure 4 indicates that the temperature gradient on the guard significantly affects the accuracy of the calculated specimen $\mathrm{k}_{\mathrm{sc}}$ using Eq. (7). Figure 5 presents the temperature distribution along the sample column and guard under some important conditions. When the guard temperature matches the bar temperature, both the top and bottom surfaces in Figure 3 have isothermal boundary conditions. This situation is equivalent to the bar, insulation and guard domains being wholly covered by a large isothermal heat source and heat sink. For the $\mathrm{k}_{\mathrm{s}}=5 \mathrm{~W} / \mathrm{m} / \mathrm{K}$ case, the temperature gradient is larger in the test sample than in the meter bars. Since the top (bottom) meter bar has a higher (lower) temperature than the corresponding height on the guard portion, radial heat flows from the top meter bar to the guard (guard to bottom meter bar). The amount of heat transferred radially, however, is affected by the amount of axial heat shunting as well. The difference of temperature gradient in the sample column and guard is the primary reason for the error. For the $k_{\mathrm{s}}=100$ $\mathrm{W} / \mathrm{m} * \mathrm{~K}$ case, the heat flow direction is reversed.

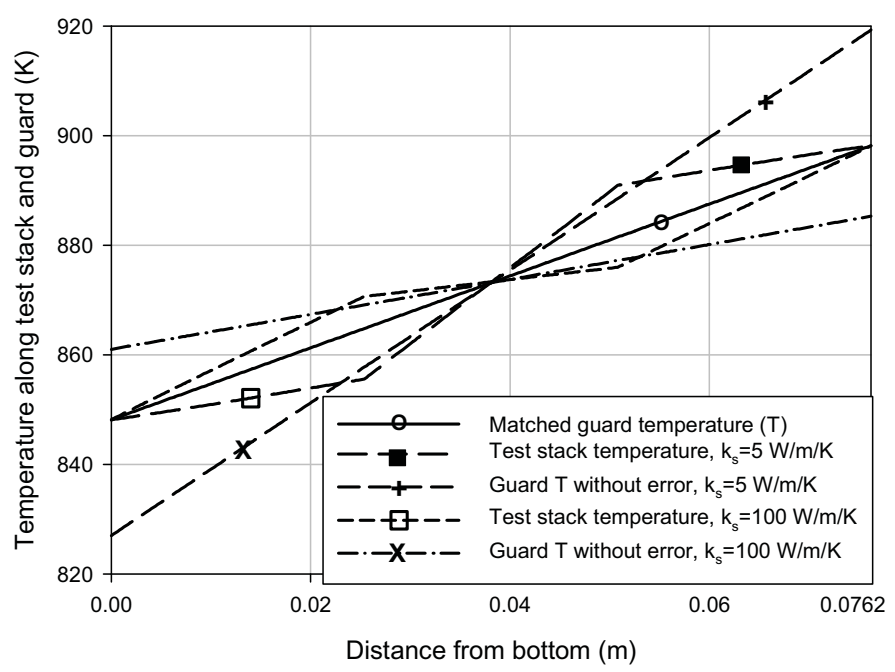

\section{FIGURE 5. TEMPERATURE DISTRIBUTION ALONG TEST STACK AND GUARD SURFACE AT DIFFERENT SITUATIONS.}

If $\Delta \mathrm{T}_{\mathrm{bg}}$ is manipulated such that the systematic error tends toward zero, as shown in Figure 4, the corresponding guard temperature gradient is superimposed in Figure 5. For such circumstances, the guard temperature gradient tends to vary from "whole sample column match" toward "specimen gradient match" but still having a slight deviation from this condition. The change of the guard temperature gradient induced a slight test stack temperature distribution change, but this variation is too small to be shown. The little redistribution of temperature minimizes the systematic error. According to Figures 4 and 5 , the optimum $\Delta \mathrm{T}_{\mathrm{bg}}$ is primarily influenced by the specimen thermal conductivity.

In the real experimental setup, the temperature gradient of the guard is easily obtained but the equal average temperature of the guard and the specimen is difficult to achieve since the temperature distribution of the specimen is affected both axially and radially. Figure 6 presents the deviation of results when guard and specimen average temperatures have a difference of $\Delta \mathrm{T}_{\mathrm{a}}$. The deviation is calculated based on the case when $\Delta \mathrm{T}_{\mathrm{a}}=0$. With this comparison, it is easy to tell whether guard temperature gradient or equal averaged temperature is more important. In this figure, $\mathrm{T}_{\mathrm{bg}}=10{ }^{\circ} \mathrm{C}$ is applied for generic consideration. From the figure one can see that the deviations are relatively small for all of the $\mathrm{k}_{\mathrm{s}}$ cases $(<0.05 \%)$. Thus, one can conclude that once an appropriate temperature gradient is imposed on the guard, the averaged temperature difference between specimen and guard does not affect the accuracy significantly, which is very convenient for simplifying the design of the apparatus as well as its working conditions. 


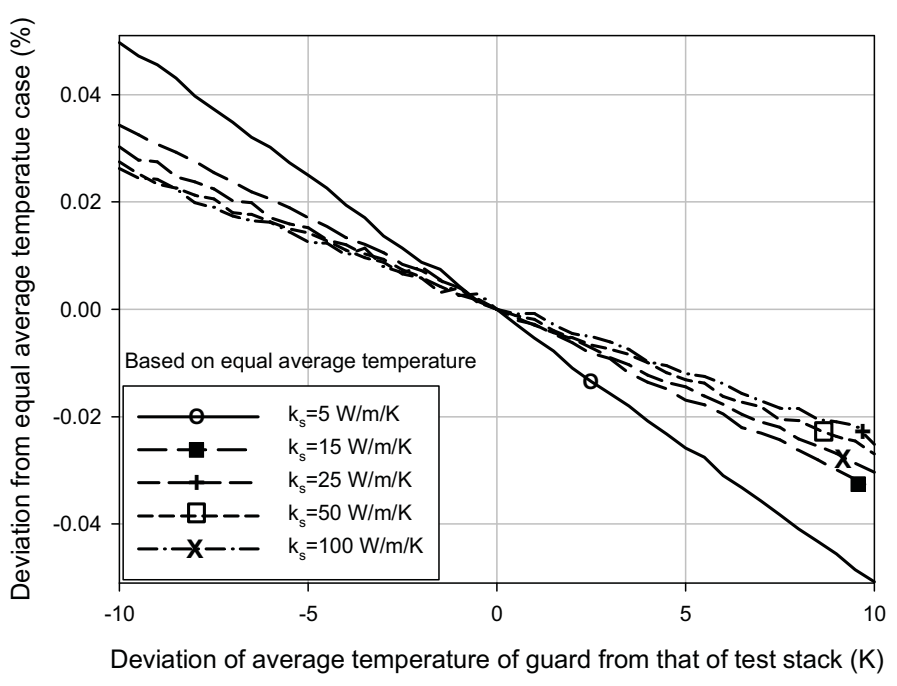

FIGURE 6. PERCENTAGE ERROR WITH RESPECT TO THE VARIATION OF $\triangle T_{M}$ BASED ON THE CALCULATED THERMAL CONDUCTIVITY WITHOUT DEVIATION.

\section{REFERENCE SAMPLE MEASUREMENT}

Because the thermal conductivity of the graphite fuel material is not yet known, several samples were selected to validate the system's performance covering the range of possible expected values which is approximately 10-60 $\mathrm{W} / \mathrm{m} / \mathrm{K}$. Table 1 shows a list of the samples selected to accomplish this testing.

The samples were selected to cover a range of expected possible thermal conductivity values. The inconel 625, SS 304 , and high purity iron have thermal conductivities in the lower, middle, and upper portions of the expected range,

\section{TABLE 2. MATERIALS SELECTED FOR APPARATUS CALIBRATION AND VALIDATION}

\begin{tabular}{|c|c|c|}
\hline Material & $\begin{array}{c}\mathrm{k}, \mathrm{W} / \mathrm{m}^{*} \mathrm{~K} \\
\left(100^{\circ} \mathrm{C}-900^{\circ} \mathrm{C}\right)\end{array}$ & Reason for testing \\
\hline Inconel 625 & $10-20$ & $\begin{array}{l}\text { Has a range slightly } \\
\text { lower than the expected } \\
\text { values for the fuel } \\
\text { compacts, data available } \\
\text { for comparison }\end{array}$ \\
\hline $\begin{array}{l}\text { Stainless steel } \\
304\end{array}$ & $14-30$ & $\begin{array}{l}\text { Well-defined thermal } \\
\text { conductivity in literature, } \\
\text { in expected range of the } \\
\text { fuel compacts }\end{array}$ \\
\hline $\begin{array}{l}\text { High purity Fe } \\
(99.95 \%)\end{array}$ & $70-30$ & $\begin{array}{l}\text { Thermal conductivity in } \\
\text { the upper expected } \\
\text { range of the fuel } \\
\text { compact, data available } \\
\text { in literature, provide } \\
\text { information about higher } \\
\text { conductivity capabilities }\end{array}$ \\
\hline
\end{tabular}

respectively. Thermal conductivity data for each of these materials is available in literature as a source of comparison.

It is worth noting that a glass-ceramic thermal conductivity reference material is also being considered for testing the low thermal conductivity range and to provide an even better validation of the system performance as it is a standard reference material which may be acquired from the Institute for Reference Materials and Measurements (IRMM). This glass-ceramic material has a thermal conductivity range of $\sim 4 \mathrm{~W} / \mathrm{m}^{*} \mathrm{~K}$ to $\sim 2.5 \mathrm{~W} / \mathrm{m}^{*} \mathrm{~K}$ between $100^{\circ} \mathrm{C}$ and $700^{\circ} \mathrm{C}$.

\section{Measurement of Stainless Steel 304}

The first sample measured in the experimental system was stainless steel 304, the same material as the meter bars. The sample was machined to the approximate size of a fuel compact with a length of $25 \mathrm{~mm}$ and a diameter of $12.3 \mathrm{~mm}$. Measurements on the stainless steel 304 sample were performed from about $\sim 200^{\circ} \mathrm{C}$ up to $\sim 600^{\circ} \mathrm{C}$ at increments of $50^{\circ} \mathrm{C}$.

The results were compared to the data from Bogaard [14] recommended by Sweet [8] in a report on comparative thermal conductivity measurement methods. The results are plotted in Fig. 7. The results vary no more than $3 \%$ from Bogaard for temperatures between $300^{\circ} \mathrm{C}$ and $600^{\circ} \mathrm{C}$. Initial testing used a $0.076 \mathrm{~mm}\left(0.003^{\prime \prime}\right)$ type $\mathrm{N}$ thermocouple which experienced significant decalibration above $600^{\circ} \mathrm{C}$ (data not shown in Fig. 7). For this reason, for all following measurement setups, $0.127 \mathrm{~mm}(0.005$ ") size type $\mathrm{N}$ (or platinum) thermocouples have been adopted for use in all critical locations (see Fig. 3, $\mathrm{z}_{1}$ thru $\mathrm{z}_{6}$ ).

\section{Measurement of $\mathbf{9 9 . 9 5 \%}$ Pure Iron}

In order to test higher thermal conductivity measurement ability, the second validation sample measured in the TFTCMS was a sample of $99.95 \%$ pure iron from ESPI Metals. The sample was cut to the approximate length of a

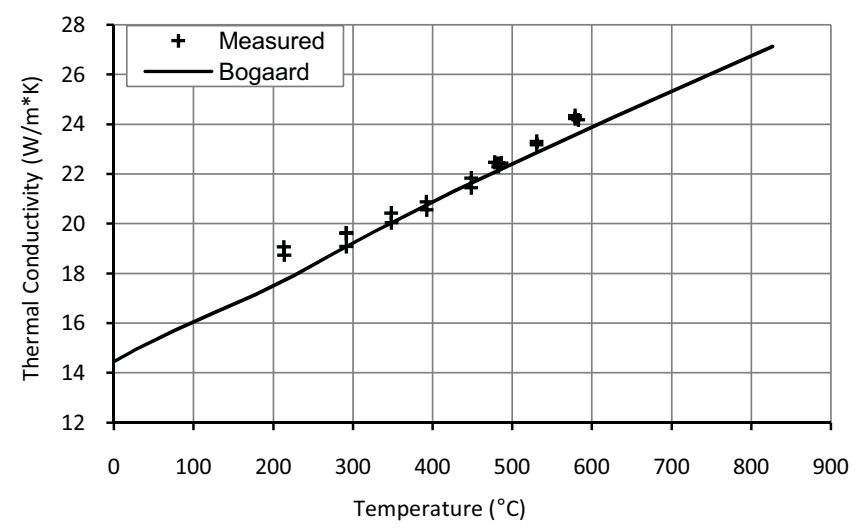

FIGURE 7. MEASURED THERMAL CONDUCTIVITY FOR STAINLESS STEEL 304 COMPARED TO PUBLISHED VALUES FROM BOGAARD [14]. 
fuel compact and the end surfaces were polished. The dimensions of the iron sample were measured to be a length of $\sim 25.648 \mathrm{~mm}$ and a diameter of $\sim 12.813 \mathrm{~mm}$ (slightly larger diameter than the meter bars).

Due to the decalibration of the smaller thermocouples used on the SS 304 sample, a larger, $0.127 \mathrm{~mm}$ (0.005") Type $\mathrm{N}$ thermocouple was used on the iron sample. Decalibration of the thermocouple is still an expected problem at high temperatures, but the larger thermocouple size is: more resistant to contamination, much easier to handle, and still small enough to not contribute much to the overall uncertainty.

Measurements were performed from $100^{\circ} \mathrm{C}$ to $600^{\circ} \mathrm{C}$ at increments of $50^{\circ} \mathrm{C}$. Each temperature was then measured a second time in reverse order. Measurement temperature were then run between $600^{\circ} \mathrm{C}$ and $800^{\circ} \mathrm{C}$, again each temperature was measured twice. Figure 8 displays the measured thermal conductivity of $99.95 \%$ pure iron compared to the values recommended by the TPRC data series [13] for $99.99 \%$ pure iron.

The results show good agreement with the published values for $99.99 \%$ pure iron. For $100^{\circ} \mathrm{C}$ to $600^{\circ} \mathrm{C}$, the difference is $<8 \%$ for all temperatures. As can be seen in the figure, for $>600^{\circ} \mathrm{C}$ the deviation becomes greater, between 5 and $10 \%$ for the first set of points collected in this range and between 12 and $14 \%$ for the second set. The results seem very promising even for a sample with a higher conductance than the meter bars. For temperatures above $600^{\circ} \mathrm{C}$, the deviation becomes larger but the overall trend of the curve is consistent.

\section{Measurement of Inconel 625}

A sample of inconel 625 was obtained from ESPI metals and was cut to a length of $25.62 \mathrm{~mm}$ with a diameter of $12.646 \mathrm{~mm}$. $0.127 \mathrm{~mm}(0.005$ ") Type $\mathrm{N}$ thermocouples were used for all temperature measurements. Measurement order and temperatures was similar to that of the pure iron sample as discussed in the previous section except the maximum

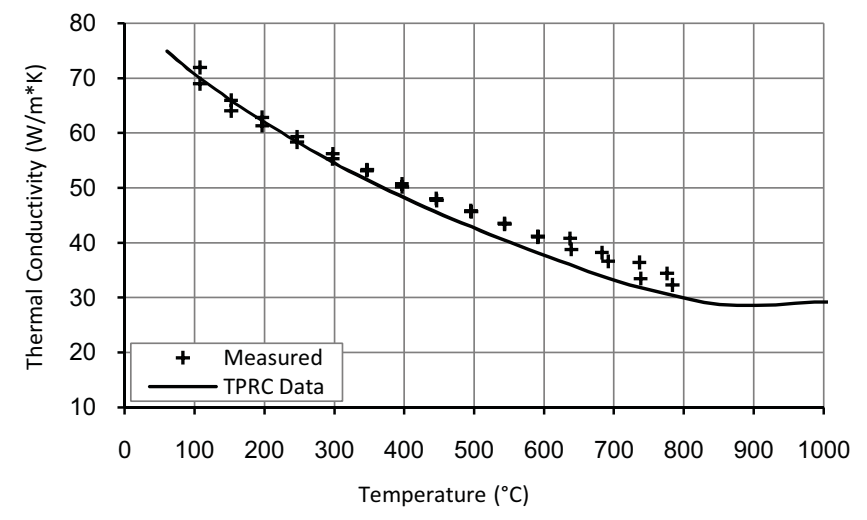

FIGURE 8. MEASURED THERMAL CONDUCTIVITY OF 99.95\% PURE IRON COMPARED TO TPRC [13] RECOMMENDED VALUES FOR 99.99\% PURE IRON. temperature was run up to $900^{\circ} \mathrm{C}$. The results are shown in Fig. 9 compared to published values. The results compare very well to the data given by www.hightempmetals.com [15]. The maximum difference is $5.8 \%$, near $600^{\circ} \mathrm{C}$, over the range of available data. The data from the Battelle Memorial Institute [16] shows a larger difference over the entire temperature range.

\section{Results Summary}

As is seen in the previous section, results for each of the validation samples are good. Although it is often recommended to match the conductance of the test sample to that of the meter bars [10], the measured values for pure iron follow a consistent trend that is close to that of the TPRC recommended values. Good performance for high ratios of thermal conductivities of the sample to the meter bars is also reported by Pillai and George [9]. The device seems to perform especially well for temperatures $<600^{\circ} \mathrm{C}$ showing good repeatability and matching well to published values.

For the lower conducting material, the system also demonstrates good performance closely following the published values up to $600^{\circ} \mathrm{C}$. For higher temperatures, the measured values begin to deviate more and show less repeatability as well. It was expected that inconel may show more variation depending on material composition and its forming process, although, the measured data follows one of the given data curves very well ( $<6 \%$ difference).

Even with these results, system validation will continue. As was mentioned in a previous section, a glass-ceramic material will be used to measure a lower ratio of sample to meter bar thermal conductivities. Continued tuning, testing, and incorporation of FEA findings will be performed to ensure system performance with unknown samples.

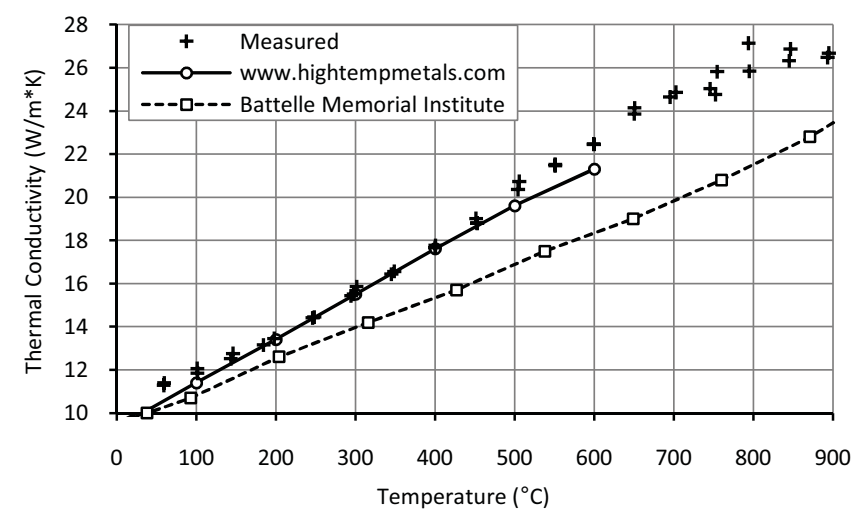

FIGURE 9. MEASURED THERMAL CONDUCTIVITY OF INCONEL 625 COMPARED TO RECOMMENDED VALUES [15-16]. 


\section{UNCERTAINTY}

A detailed discussion of the determinate uncertainty related to this system is found in [1] where the results of a propagation of error analysis are presented as well. These results were found using equations (1) and (2) and assuming that all the independent variables in these equations are uncorrelated with the exception of the meter bar thermal conductivity to come up with the overall variance of $k_{s}$ as:

$$
\begin{aligned}
& {\sigma_{k_{s}}}{ }^{2}={\sigma_{k_{m}}}{ }^{2}+\frac{1}{2}{\sigma_{A_{m}}}^{2}+\frac{1}{2}{\sigma_{\Delta T_{m}}}^{2}+\frac{1}{2}{\sigma_{\Delta Z_{m}}}^{2} \\
& +{\sigma_{A_{S}}}^{2}+{\sigma_{\Delta T_{S}}}^{2}+\sigma_{\Delta Z_{s}}{ }^{2}
\end{aligned}
$$

Using this equation with the individual error contributions, the overall determinate uncertainty was found to be $\sim 5.6 \%$ (excluding the error associated with the meter bar thermal conductivity the error becomes $\sim 2.5 \%$ ).

This uncertainty analysis is basically independent of temperature. The main contribution that increased temperature gives to the uncertainty is from the change of material properties in the measurement section. In particular an increase of temperature generally means an increase of most insulation materials. As the insulation's resistance to heat flow is decreased, the error contribution from a non-uniform heat flux will increase. Recommended temperature limits for the stainless steel and nickel components are close to $900^{\circ} \mathrm{C}$. The type and size of thermocouple also needs to be selected based on the desired temperature range. The larger deviations seen at temperatures greater than $600^{\circ} \mathrm{C}$ for the validation sample is mainly attributed to the $0.127 \mathrm{~mm}\left(0.005^{\prime \prime}\right)$ Type $\mathrm{N}$ thermocouples used.

TABLE 3. DETERMINATE UNCERTAINTIES IN MEASURED PARAMETERS FOR $\mathrm{K}_{S}$ SHOWING CONTRIBUTION TO OVERALL UNCERTAINTY.

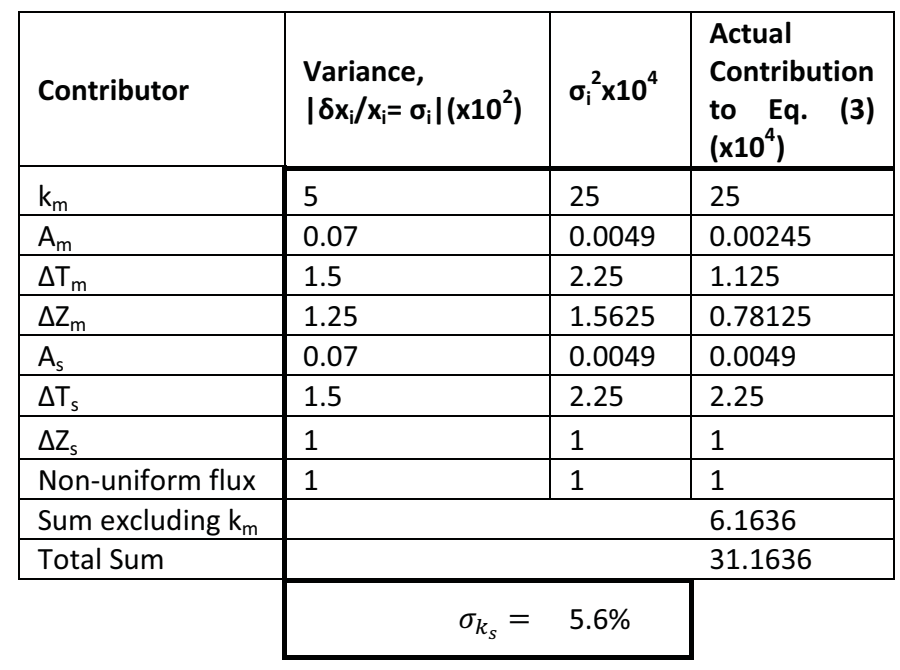

\section{CONCLUSION}

A complete system to measure the thermal conductivity of nuclear fuel compacts has been designed and built. FEA of the system have revealed optimum operating conditions and the effects of various temperature conditions that the system may be operated under. A better understanding of ASTM recommended operating conditions has been obtained revealing that the guard temperature gradient has a more dramatic effect on system results than does the guard average temperature. Initial testing has shown good results for stainless steel 304 falling within $3 \%$ of published values for $<600^{\circ} \mathrm{C}$. Results for varying sample to meter bar thermal conductivities are within $8 \%$ of published values for high purity iron and within $6 \%$ for inconel 625 (for $<600^{\circ} \mathrm{C}$ ). Determinate uncertainty has been calculated to be $2.5 \%$ excluding the uncertainty in the reference sample thermal conductivity for an overall uncertainty of $5.6 \%$. Further calibration will be performed on a certified reference sample as well as the incorporation of the results demonstrated by the FEA.

\section{ACKNOWLEDGEMENTS}

Work supported by the U.S. Department of Energy, Office of Nuclear Energy, under DOE Idaho Operations Office Contract DE-AC07-05ID14517.

Work performed by Colby Jensen is supported under a Department of Energy Nuclear Energy University Programs Graduate Fellowship.

\section{REFERENCES}

[1] Jensen, C., Xing, C., Ban, H., Barnes, C., and Phillips, J., 2010, "A Thermal Conductivity Measurement System for Fuel Compacts," International Mechanical Engineering Congress and ExpositionVancouver, British Columbia.

[2] Van Dusen, M., and Shelton, S., 1934, "Apparatus for measuring thermal conductivity of metals up to $600 \mathrm{C}$," Bureau of Standards Journal of Research, 12, pp. 429-440.

[3] Ballard, S., McCarthy, K., and Davis, W., 1950, "A Method for Measuring the Thermal Conductivity of Small Samples of Poorly Conducting Materials such as Optical Crystals," Review of Scientific Instruments, 21, p. 905.

[4] Morris, R., and Hust, J., 1961, "Thermal Conductivity Measurements of Silicon from 30 to 425 C," Physical Review, 124(5), pp. 1426-1430.

[5] Francl, J., and Kingery, W., 1954, "Apparatus for Determining Thermal Conductivity by a Comparative Method," Journal of the American Ceramic Society, 37.

[6] Mirkovich, V., 1965, "Comparative Method and Choice of Standards for Thermal Conductivity Determinations," Journal of the American Ceramic Society, 48(8), pp. 387-391.

[7] Laubitz, M. J., 1969, "Measurements of the Thermal Conductivity of Solids at High Temperatures using Steady State Linear and Quasilinear Heat Flow," Thermal 
Conductivity, R. P. Tye, ed., Academic Press, London, pp. 111-183.

[8] Sweet, J., Roth, E., Moss, M., Haseman, G., and Anaya, J., 1986, "Comparative Thermal Conductivity Measurements at Sandia National Laboratories," No. SAND86-0840, Sandia National Laboratory, Albuquerque, NM.

[9] Pillai, C., and George, A., 1991, "An Improved Comparative Thermal Conductivity Apparatus for Measurements at High Temperatures," International Journal of Thermophysics, 12(3), pp. 563-576.

[10] ASTM Standard E1225, 1987 (2004), "Standard Test Method for Thermal Conductivity of Solids by Means of the Guarded-Comparative-Longitudinal Heat Flow Technique," ASTM International, West Conshohocken, PA.

[11] Babelot, J., Gaal, P., Van Geel, J., and Schmidt, H., 1994, "A Heat Flow Comparator for Measuring the Thermal Conductivity of Highly Radioactive Specimens," Proc. International Thermal Conductivity Conference 22, T. W. Tong, ed., Tecnomic Publishing Company, pp. 913-919.

[12] Didion, D., 1968, "An Analysis and Design of a Linear Guarded Cut-bar Apparatus for Thermal Conductivity Measurements," No. AD-665789, National Technical Information Service, Springfield, VA.

[13] Touloukian, Y., Powell, R., Ho, C., and Klemens, P., 1970, Thermal Conductivity: Metallic Elements and Alloys, IFI/Plenum Press, New York.

[14] Bogaard, R. H., 1985, "Thermal Conductivity of Selected Stainless Steels," Proc. International Thermal Conductivity Conference 18, T. Ashworth, and D. R. Smith, eds., Plenum Press, pp. 175-185.

[15] http://www.hightempmetals.com/techdata/hitempInconel 625data.php, "Inconel 625 Technical Data."

[16] http://www.upmet.com/625-physical.shtml, "Inconel 625 Sheet \& Coil Properties." 